\title{
CRÓNICA DE JURISPRUDENCIA DEL TRIBUNAL EUROPEO DE DERECHOS HUMANOS, MAYO-AGOSTO 2018
}

SALVADOR CUENCA CURBELO'

Salvador.CuencaCurbelo@echr.coe.int

I. INTRODUCCIÓN. II. PRINCIPALES SENTENCIAS Y DECISIONES DEL TEDH: 1. Derecho a la vida (artículo 2 del CEDH). 2. Prohibición de la esclavitud y del trabajo forzado (artículo 4 del CEDH). 3. No hay pena sin ley (artículo 7 del CEDH). 4. Derecho al respeto a la vida privada y familiar (artículo 8 del CEDH). 5. Garantías de procedimiento en caso de expulsión de extranjeros (artículo 1 del Protocolo $n .{ }^{\circ}$ 7). III. REFERENCIAS AL DERECHO DE LA UE EN LA JURISPRUDENCIA DEL TEDH. IV. ESPAÑA Y EL TEDH.

1 Letrado del Tribunal Europeo de Derechos Humanos. 


\section{INTRODUCCIÓN}

La presente crónica de jurisprudencia tiene el objeto de presentar algunas de las resoluciones más relevantes dictadas por el Tribunal Europeo de Derechos Humanos (en adelante, TEDH o el Tribunal) durante el periodo comprendido entre los meses de mayo y agosto de 2018. Durante este periodo, más concretamente el 1 de agosto de 2018, el Protocolo n. ${ }^{\circ} 16$ al Convenio entró en vigor para los diez Estados parte que lo han ratificado ${ }^{2}$. Este protocolo abre la posibilidad a que los órganos jurisdiccionales de mayor rango de los Estados puedan solicitar al Tribunal que emita opiniones consultivas sobre cuestiones relativas a la interpretación o a la aplicación de los derechos y libertades definidos en el Convenio o sus protocolos.

En cuanto a la jurisprudencia del TEDH en el segundo cuatrimestre de 2018, en primer lugar se realizará un análisis de las sentencias más relevantes por su impacto y trascendencia en el desarrollo del ámbito de aplicación y contenido de los derechos reconocidos en el Convenio Europeo de Derechos Humanos (en adelante, CEDH o el Convenio). En este número de la revista se presentan sentencias relativas a los arts. 2 (derecho a la vida), 4 (prohibición de la esclavitud y del trabajo forzado), 7 (no hay pena sin ley) y 8 (derecho al respeto a la vida privada y familiar) del Convenio y al art. 1 del Protocolo n. ${ }^{\circ}$ 7 (garantías de procedimiento en caso de expulsión de extranjeros), por orden de aparición de los artículos en el Convenio.

En la segunda sección, se analizarán dos sentencias en las que el TEDH examinó instrumentos legales y jurisprudencia de la Unión Europea (en adelante, UE) para fundamentar sus fallos. Las sentencias citadas versan sobre las garantías de un proceso equitativo reconocidas en el art. 6(3)(a) y (e) del Convenio y sobre la protección de la propiedad (art. 1 del Protocolo n. ${ }^{\circ} 1$ ).

Por último, la tercera sección abordará las resoluciones más relevantes dictadas por el TEDH en demandas presentadas contra España. Teniendo en cuenta que durante el periodo de referencia no se dictó ninguna sentencia, se hará únicamente referencia a dos decisiones de inadmisibilidad.

\section{PRINCIPALES SENTENCIAS Y DECISIONES DEL TEDH}

\section{DERECHO A LA VIDA (ARTíCULO 2 DEL CEDH)}

En el primer caso que se expone, Mazepa y otros contra Rusia ${ }^{3}$, el TEDH se pronunció sobre el alcance de la investigación llevada a cabo para esclarecer

2 Albania, Armenia, Estonia, Finlandia, Francia, Georgia, Lituania, San Marino, Eslovenia y Ucrania.

3 TEDH, Mazepa and Others. v. Russia, no. 15086/07, 17 de julio de 2018. Nótese que, a la fecha de redacción de la presente crónica, esta sentencia no ha alcanzado firmeza de conformidad con lo establecido en el art. 44(2) del Convenio. 
el asesinato por encargo de una conocida periodista. La víctima, Anna Politkovskaya, fue asesinada el 7 de octubre de 2006 en el ascensor de su vivienda en Moscú. Era una periodista de investigación, firme crítica del presidente $\mathrm{Pu}$ tin, que se dio a conocer al dar cobertura a las presuntas violaciones de derechos humanos cometidas en el transcurso de una operación antiterrorista en la región de Chechenia. Varios familiares de la periodista (madre, hermana e hijos) presentaron una demanda ante el TEDH aduciendo que la investigación sobre su muerte no había sido efectiva ya que no había permitido identificar a las personas que habían ordenado el asesinato y no se había investigado suficientemente la posible participación de los servicios de seguridad del Estado.

El mismo día en que se cometió el asesinato, la Fiscalía abrió una investigación sobre los hechos. Posteriormente varias personas fueron acusadas por el asesinato de la periodista y se inició un procedimiento penal contra ellos. Un primer procedimiento judicial finalizó con la absolución de las cuatro personas que habían sido acusadas, sentencia que fue anulada en apelación por el Tribunal Supremo. El caso fue entonces remitido al tribunal de instancia para que procediera a examinarlo de nuevo. Posteriormente, a petición de los familiares de la víctima, el Tribunal Supremo ordenó que el caso se volviera a transferir a la Fiscalía para que hiciera una investigación más detallada.

La investigación dio lugar a nuevos hallazgos y derivó en nuevas imputaciones. El 29 de mayo de 2014 un jurado popular declaró a los cinco coacusados culpables de un delito de asesinato. La sentencia, dictada el 9 de junio de 2014 y posteriormente confirmada por el Tribunal Supremo el 26 de junio de 2015, determinó que una persona sin identificar había pagado una importante cantidad de dinero por el asesinato de la periodista al estar descontento con sus publicaciones. Dos de los acusados fueron condenados a cadena perpetua.

El TEDH examinó las quejas de los demandantes y concluyó que se había producido una violación del art. 2 del Convenio en su «aspecto procesal». En primer lugar, a pesar de que las obligaciones procesales impuestas por el art. 2 del Convenio son obligaciones de medios y no de resultados y de que la investigación había llevado a la identificación y condena de cinco personas directamente implicadas en el asesinato, el TEDH consideró que la investigación no había sido adecuada por no haber permitido identificar a aquellas otras personas que habían encargado el asesinato ${ }^{4}$. Aunque la investigación había concluido con resultados tangibles, no se habían llevado a cabo verdaderos esfuerzos para esclarecer la autoría intelectual del crimen, particularmente teniendo en cuenta que se trataba de un asesinato por encargo de una figura

4 TEDH, Mazepa and Others v. Russia, cit., párrs. 75-78. 
pública y, por ello, el objetivo de la investigación debía haber ido más allá de la mera identificación de los sicarios.

El TEDH, haciendo referencia a la Recomendación (2016) 4 del Comité de Ministros del Consejo de Europa ${ }^{5}$, puso especial énfasis en la condición de periodista de investigación de la víctima, reiterando que en aquellos casos donde la víctima de asesinato sea un o una periodista es de vital importancia comprobar la posible vinculación del crimen con su actividad profesional ${ }^{6}$.

El TEDH también destacó que las conclusiones de este tipo de investigaciones en todo caso se deben basar en un análisis exhaustivo, objetivo e imparcial de todos los elementos relevantes y, por ende, las autoridades debían haber investigado las acusaciones vertidas por los demandantes que implicaban a las fuerzas de seguridad y autoridades de Chechenia en el asesinado de Anna Politkovskaya, incluso si eventualmente se demostraran infundadas. El TEDH criticó la poca información sobre el alcance de la investigación presentada por Rusia en el marco del procedimiento y que no hubiera justificado por qué se había seguido una única línea de investigación.

Por otro lado, el TEDH también consideró que Rusia no había aportado argumentos sólidos que justificaran la excesiva duración de la investigación, que comenzó el mismo día del asesinato de la periodista y, a tenor de lo expresado por el Estado demandado en sus observaciones y a pesar de las mencionadas condenas, todavía continuaba oficialmente abierta, vulnerando así la exigencia del art. 2 del Convenio de que toda investigación se deba llevar a cabo con prontitud y dentro de un plazo razonable ${ }^{7}$.

\section{PROHIBICIÓN DE LA ESCLAVITUD Y DEL TRABAJO FORZADO (ARTÍCULO 4 DEL CEDH)}

El segundo caso que se presenta en la presente crónica es S.M. contra Croacia $^{8}$, relativo a la trata de personas y explotación sexual con fines de prostitución en el marco del art. 4 del Convenio. A instancias de la demandante, de nacionalidad croata, se inició un procedimiento penal contra un

5 Recomendación CM/Rec (2016)4 sobre protección del periodismo y la seguridad de periodistas y otros profesionales de los medios de comunicación.

6 TEDH, Mazepa and Others v. Russia, cit., párr. 73.

7 Ibid., párrs. 80-82.

8 TEDH, S.M. v. Croatia, no. 60561/14, 19 de julio de 2018. Nótese que, a la fecha de redacción de la presente crónica, esta sentencia no ha alcanzado firmeza de conformidad con lo establecido en el art. 44(2) del Convenio. 
hombre, antiguo policía con el que había mantenido una relación, al que acusaba de haberla forzado (física y psicológicamente) a prostituirse. Las autoridades abrieron una investigación que llevó a la imputación del acusado por un delito agravado de prostitución. La Oficina para los Derechos Humanos y de las Minorías croata reconoció la condición de víctima de trata a la demandante.

En febrero de 2013 el juzgado de lo penal correspondiente absolvió al imputado apreciando que no se había probado que la demandante hubiera sido obligada a prostituirse. El tribunal destacó que el acusado solo había sido imputado por un delito en su tipo agravado y, por tanto, no se le podía condenar por el delito en su forma básica. A pesar de ello, el tribunal consideró probado que el acusado había organizado una red de prostitución para la que había contratado a la demandante, que prestaba servicios sexuales en el piso que compartían. El tribunal también destacó que el testimonio de la demandante había sido incoherente, mostrando dudas y falta de seguridad. La sentencia fue confirmada en apelación.

El TEDH, en primer lugar, examinó la aplicabilidad del art. 4 del Convenio al caso de autos. Aunque en anteriores ocasiones el TEDH ya había tenido la ocasión de abordar casos de trata de seres humanos, esta es la primera vez en que ha tenido que examinar la aplicabilidad de dicho artículo a un caso de explotación sexual de mujeres con fines de prostitución. Así, el TEDH, a la vista de su obligación de interpretar el Convenio de acuerdo con las condiciones actuales, concluyó que tanto la trata como la explotación de la prostitución entraban por sí mismas en el ámbito de aplicación de dicho art. 4, sin necesidad de que debieran ser calificadas como «esclavitud», «servidumbre» o «trabajo forzado». El TEDH hizo referencia a numerosos instrumentos internaciones - tales como el Protocolo de Palermo9?, el Convenio del Consejo de Europa sobre la Lucha contra la Trata de Seres Humanos, el Convenio para la Represión de la Trata de Personas y de la Explotación de la Prostitución Ajena, o la Convención sobre la Eliminación de Todas las Formas de Discriminación contra la Mujer-, en base a los que destacó que era irrelevante que la demandante fuera nacional del Estado demandando y que por ende no existiera un «elemento internacional» ${ }^{10}$.

9 Protocolo para prevenir, reprimir y sancionar la trata de personas, especialmente mujeres y niños, que complementa la Convención de las Naciones Unidas contra la Delincuencia Organizada Transnacional.

10 TEDH, S.M. c. Croacia, cit., párr. 54. 
En cuanto al fondo del asunto el TEDH reiteró los principios fijados en su jurisprudencia en el contexto del tráfico de personas ${ }^{11}$, aplicables también al presente caso. El TEDH recalcó las obligaciones positivas de los Estados a la hora combatir el tráfico de seres humanos, tales como la obligación de desarrollar un marco legislativo y administrativo apropiado que prohíba y sancione la trata de personas así como de tomar medidas para la protección de las víctimas, y subrayó que también implicaba una obligación "procesal» de llevar a cabo una investigación efectiva sobre aquellos casos en los que existieran sospechas de que el art. 4 hubiera sido vulnerado.

En respuesta a las quejas planteadas por la demandante, el análisis de las circunstancias específicas del caso giró en torno a tres ejes fundamentales: si existía un marco jurídico y normativo apropiado para la protección de los derechos de la demandante, si la demandante había recibido ayuda y apoyo para mitigar el miedo y la presión que había sentido mientras testificaba contra el acusado, y si las autoridades nacionales habían cumplido con sus obligaciones procesales.

Las dos primeras preguntas (relativas a las obligaciones positivas del Estado) se respondieron de forma positiva para el Estado demandado. Por un lado, el TEDH consideró que Croacia contaba con un marco jurídico adecuado. El TEDH hizo hincapié en el hecho de que conductas como la explotación de la prostitución, la trata de seres humanos, la esclavitud, el trabajo forzado o explotar la prostitución de otra persona estuvieran tipificadas como delito en el Código Penal (independientemente de que hubiera existido consentimiento por parte de la víctima), de que existieran disposiciones sobre los derechos de las víctimas en la legislación procesal penal y de que las autoridades de Croacia hubieran adoptado acciones para prevenir y combatir el tráfico de seres humanos. Por otro lado, el TEDH concluyó que las autoridades habían prestado apoyo y asistencia suficiente a la demandante, que incluyó el reconocimiento de su condición de víctima de trata, asesoramiento y asistencia jurídica gratuita y, cuando la demandante lo pidió, la retirada del acusado de la sala de audiencias para que la demandante pudiera presentar prueba sin su presencia.

Por el contrario, el TEDH consideró que Croacia no había cumplido con sus obligaciones "procesales», motivo por el que determinó que se había violado el art. 4 del Convenio ${ }^{12}$. El TEDH reconoció que la policía y las autoridades judiciales habían actuado con celeridad. No obstante, criticó que

11 Véase TEDH, Rantsev v. Cyprus and Russia, no. 25965/04, 7 de enero de 2010; y Chowdury and Others v. Greece, no. 21884/15, 30 de marzo de 2017.

12 TEDH, S.M. v. Croatia, cit., párrs. 75-80. 
únicamente se hubieran presentado como testigos a la misma demandante y una amiga, no habiéndose tomado declaración a un conjunto de testigos relevantes como los propios clientes de la demandante, su madre, vecinos u otras personas que habían estado en contacto con ella y que podían haber testificado sobre la relación entre la demandante y el acusado o sobre el posible empleo de violencia o intimidación. El TEDH también enumeró una serie de acciones que las autoridades nacionales podrían haber llevado a cabo para probar la alegada situación de vulnerabilidad de la víctima o la presunta coacción ejercida por parte del acusado. Todo ello llevó a la conclusión de que las autoridades nacionales no habían hecho un intento serio de investigar en profundidad todas las circunstancias relevantes para la resolución del caso. Tampoco habían valorado las repercusiones del trauma psicológico en la capacidad de la demandante de relatar las circunstancias de su explotación de forma clara y consistente y el impacto que la presencia del acusado en la sala de audiencias (antes de que fuera desalojado) pudo haber tenido en la demandante.

\section{NO HAY PENA SIN LEY (ARTÍCULO 7 DEL CEDH)}

En el caso G.I.E.M. S.R.L. y otros contra Italia ${ }^{13}$ recayó sentencia de Gran Sala, en la que el TEDH tuvo la ocasión de pronunciarse sobre el decomiso de bienes en ausencia de una condena penal y el principio de legalidad. La demanda fue interpuesta por cuatro empresas y un ciudadano italiano (Sr. Gironda). Resoluciones judiciales ordenando el decomiso de terrenos y construcciones fueron dictadas contra los demandantes con motivo del desarrollo ilegal de varios terrenos y la comisión de irregularidades urbanísticas. Sin embargo, no se iniciaron procedimientos penales contra una de las empresas (G.I.E.M. S.r.l.), las otras tres empresas no participaron en los procedimientos penales iniciados contra sus directores o representantes y, aunque el Sr. Gironda había sido acusado en un procedimiento penal, se decretó el archivo del procedimiento al haber prescrito el delito. La Gran Sala determinó que había existido una violación del art. 1 del Protocolo n. ${ }^{\circ} 1$ (protección de la propiedad) y una violación del art. 7 en relación a las cuatro empresas demandantes. En lo que respecta al Sr. Gironda, la Gran Sala concluyó que había existido una violación del art. 1 del Protocolo n. ${ }^{\circ} 1$ y del art. 6(2) del Convenio (presunción de inocencia), pero que no había existido una violación del art. 7 del Convenio.

13 TEDH, G.I.E.M. S.R.L. and Others v. Italy [GC], nos. 1828/06 and 2 others, 28 de junio de 2018. 
En el análisis del derecho aplicable al caso de autos el TEDH destacó varios instrumentos de la UE relacionados con el decomiso de bienes. El TEDH hizo referencia a la Directiva 2014/42/UE sobre el embargo y el decomiso de los instrumentos y del producto del delito en la Unión Europea ${ }^{14}$ y a las Decisiones Marco del Consejo 2001/500/JAI ${ }^{15}$ y 2005/212/JAI ${ }^{16}$.

En lo concerniente al art. 7 del Convenio, la importancia de esta sentencia radica en que el TEDH confirma y clarifica su jurisprudencia precedente tras los pronunciamientos dictados en los casos Sud Fondi S.R.L. y otros ${ }^{17}$ y Varvara $^{18}$, ambos contra Italia. En primer lugar, el TEDH examinó la aplicabilidad del art. 7 al caso concreto. Con el objeto de confirmar si el decomiso de bienes constituía una "pena», la Gran Sala reiteró los criterios que de acuerdo a su jurisprudencia se deben utilizar para valorar el carácter "penal» de la sanción, esto es: si la medida se impuso tras una decisión que declarara la culpabilidad de una persona por una infracción penal, la naturaleza y el objeto de la medida en cuestión, su caracterización con arreglo a derecho nacional, los procedimientos aplicables a la adopción e implementación de la medida, y su gravedad ${ }^{19}$. Cabe destacar que la Gran Sala confirmó que el primero de los citados criterios era únicamente uno de los criterios a tener en cuenta y no necesariamente el criterio decisivo ${ }^{20}$. En este sentido, el TEDH concluyó que el decomiso acordado tenía relación con la comisión de una infracción penal de acuerdo con disposiciones legales de carácter general y, por tanto, el art. 7 era aplicable al presente caso.

En cuanto al fondo de la queja, la Gran Sala confirmó que el art. 7 requería que las medidas de decomiso fueran previsibles para los demandantes e impedía que se tomaran decisiones que impusieran medidas en ausencia

14 Directiva 2014/42/UE del Parlamento Europeo y del Consejo, de 3 de abril de 2014, sobre el embargo y el decomiso de los instrumentos y del producto del delito en la Unión Europea (DO L 127, de 29 de abril de 2014, p. 39).

15 Decisión Marco 2001/500/JAI del Consejo, de 26 de junio de 2001, relativa al blanqueo de capitales, la identificación, seguimiento, embargo, incautación y decomiso de los instrumentos y productos del delito (DO L 182, de 5 de julio de 2001, p. 1).

16 Decisión Marco 2005/212/JAI del Consejo, de 24 de febrero de 2005, relativa al decomiso de los productos, instrumentos y bienes relacionados con el delito (DO L 68, de 15 de marzo de 2005, p. 49).

17 TEDH, Sud Fondi S.R.L. and Others v. Italy (dec.), no. 75909/01, 30 de agosto de 2007; y Sud Fondi S.R.L. and Others v. Italy, no. 75909/01, 20 de enero de 2009.

18 TEDH, Varvara v. Italy, no. 17475/09, 29 de octubre de 2013.

19 TEDH, G.I.E.M. S.R.L. and Others v. Italy [GC], cit., párr. 211.

20

Ibid., párr. 215. 
de un vínculo subjetivo (mental link) que revelara un elemento de responsabilidad en su conducta. En cuanto a si dicho vínculo se podía considerar cumplido cuando ninguno de los demandantes había sido formalmente condenado, la Gran Sala clarificó que no era obligatorio que la requerida «declaración de responsabilidad penal» fuera necesariamente dictada por tribunales penales, aunque ello fuera lo más frecuente. De esta forma, medidas de decomiso como las del caso de autos no debían ir necesariamente acompañadas de condenas dictadas por parte de tribunales penales. No obstante, el art. 7 sí exigía, cuanto menos, una «declaración formal de responsabilidad penal» respecto de los demandantes. En el caso concreto, el TEDH destacó que tal declaración no se había producido en relación con las empresas demandantes (contra las que no se había iniciado procedimiento alguno), confirmando que la personalidad jurídica de dichas empresas se diferenciaba de la de sus representantes. En opinión del TEDH, el principio de legalidad prohibía la condena de las compañías demandantes por la comisión de delitos imputables a sus directores. En cuanto al Sr. Gironda, el TEDH destacó que aunque los procedimientos seguidos contra él habían sido archivados por existir prescripción de los delitos, todos los elementos del tipo habían sido confirmados por el Tribunal de Casación, conclusiones que se podían considerar como constitutivas (en sustancia) de una "condena" para los fines del art. 7 del Convenio.

Como ya se ha avanzado anteriormente, el TEDH también concluyó que había existido una vulneración del art. 1 del Protocolo $n^{\circ} 1$ (protección de la propiedad) de todos los demandantes. El TEDH, en primer lugar, no consideró necesario pronunciarse sobre si la violación del art. 7 tenía como consecuencia automática que las medidas de decomiso impugnadas carecieran de base legal. En cuanto a la finalidad de las medidas, aunque el TEDH subrayó la innegable legitimidad de las políticas en favor de la protección del medio ambiente, dejó dudas sobre si el decomiso realmente contribuía a la consecución de tal fin. En cualquier caso, el TEDH concluyó que las medidas no habían sido proporcionadas, para lo que tomó en consideración varios factores tales como el grado de culpabilidad o negligencia de los demandantes o, por lo menos, la relación entre su conducta y el delito en cuestión y la existencia de suficientes garantías procesales.

Por último, el TEDH destacó que se había producido una vulneración del derecho a la presunción de inocencia del Sr. Gironda en tanto que el Tribunal de Casación había dictado la citada declaración de culpabilidad a pesar de que el delito ya había prescrito. 


\section{DERECHO AL RESPETO A LA VIDA PRIVADA Y FAMILIAR (ARTÍCULO 8 DEL CEDH)}

Otra de las sentencias destacas en este número es M.L. y W.W. contra Alemania ${ }^{21}$. Los demandantes habían sido condenados a cadena perpetua por el asesinato de un conocido actor en 1991. Su juicio recibió una gran atención por parte de los medios de comunicación en su momento. Mientras los demandantes cumplían sus condenas intentaron en varias ocasiones - siempre sin éxito- que se reabriera el procedimiento. En agosto de 2007 y enero de 2008, respectivamente, fueron puestos en libertad condicional.

Los demandantes solicitaron a varios medios de comunicación que habían informado sobre su caso que hicieran anónima la información personal de la que disponían sobre ellos en sus archivos en línea, petición que justificaron con motivo de su reinserción social. Ante la negativa por parte de los medios, los demandantes iniciaron procedimientos judiciales, que finalizaron con la desestimación de sus pretensiones por parte del Tribunal Federal de Justicia.

En el procedimiento ante el TEDH los demandantes se quejaron de que la negativa del Tribunal Federal de Justicia a prohibir que los medios de comunicación mantuvieran en sus portales de internet la información relativa a su condena y el procedimiento penal seguido contra ellos suponía una nueva estigmatización que dificultaba su reinserción en la sociedad, particularmente cuando ya habían cumplido su condena y ésta se remontaba a más de quince años atrás. Los demandantes argumentaron que únicamente solicitaban que la información fuera anónima (y no que se eliminara), por lo que las noticias satisfarían el interés público de igual manera. De conformidad con el art. 36(2) del Convenio y el art. 44 del Reglamento del TEDH los medios de comunicación contra los que los demandantes habían iniciado acciones judiciales en Alemania fueron autorizados a participar en el procedimiento.

El TEDH, en primer lugar, afirmó una vez más que la protección de datos de carácter personal es de una importancia fundamental para el disfrute del derecho a la vida privada de las personas y destacó la contribución de la puesta a disposición de archivos en internet a la preservación y la accesibilidad a la información y actualidad. El TEDH hizo referencia a varios instrumentos de la UE en materia de protección de datos ${ }^{22} \mathrm{y}$ a la sentencia del Tribunal de

21 TEDH, M.L. and W.W. v. Germany, nos. 60798/10 and 65599/10, 28 de junio de 2018.

22 Particularmente al Reglamento (UE) 2016/679 del Parlamento Europeo y del Consejo, de 27 de abril de 2016, relativo a la protección de las personas físicas en lo que 
Justicia de la Unión Europea (TJUE) en el asunto Google Spain ${ }^{23}$, que recibió una atención destacada.

En cuanto al fondo del asunto, el TEDH comenzó destacando que los procedimientos judiciales se habían dirigido contra los medios de comunicación que habían publicado información relativa a los demandantes y no contra los motores de búsqueda de internet. Dichos motores de búsqueda tendrían el efecto de amplificar la posible injerencia en la vida privada al aumentar la difusión de las noticias, por lo que sus obligaciones podrían diferenciarse de aquellas del editor de origen de la información. Por consiguiente, la ponderación de los intereses en juego podría dar lugar a resultados diferentes si se tratara de una demanda dirigida contra el editor inicial de la información o contra los motores de búsqueda. Tras realizar dicha clarificación sobre el alcance del caso de autos, el TEDH examinó las circunstancias concretas aplicando los criterios pertinentes - ya consolidados en su jurisprudenciapara llevar a cabo la ponderación del derecho al respeto de la vida privada y el derecho a la libertad de expresión, esto es, la contribución a un debate de interés general, la notoriedad de la persona aludida y el objeto del reportaje, el comportamiento anterior de la persona en cuestión, y el contenido, la forma y las repercusiones de la publicación.

En cuanto al primero de los criterios, el TEDH destacó que la disponibilidad de los reportajes en las páginas web de los medios de comunicación contribuía a un debate de interés general. El público tiene un interés no solamente en ser informado sobre eventos de actualidad sino también a poder hacer búsquedas sobre eventos pasados. Toda medida que limite el acceso a la información debe estar justificada por necesidades imperiosas, jugando la prensa un rol fundamental en toda sociedad democrática. La inclusión en el reportaje de elementos individualizados, tales como el nombre completo de la persona en cuestión, constituiría un aspecto importante del trabajo de la prensa.

Por otro lado, el TEDH también resaltó que aunque los demandantes no eran conocidos antes de la comisión del crimen, el proceso en el que se les condenó suscitó una atención considerable en la opinión pública en razón de

respecta al tratamiento de datos personales y a la libre circulación de estos datos y por el que se deroga la Directiva 95/46/CE (DO L 119, de 4 de mayo de 2016, p. 1); y a la propia Directiva 95/46/CE del Parlamento Europeo y del Consejo, de 24 de octubre de 1995 , relativa a la protección de las personas físicas en lo que respecta al tratamiento de datos personales y a la libre circulación de estos datos (DO L 281, de 23 de noviembre de 1995, p. 31).

23 Sentencia del Tribunal de Justicia de 13 de mayo de 2014, Google Spain y Google, C-131/12, EU:C:2014:317. 
la naturaleza y las circunstancias del asesinato y de la celebridad de la víctima. A dicha notoriedad también contribuyó el comportamiento de los propios demandantes, que no solo intentaron la reapertura de sus procedimientos en numerosas ocasiones, sino que se dirigieron a la prensa, a la que incluso transmitieron documentos, con el propósito de que informaran de sus pretensiones.

Por último, el TEDH subrayó que los textos escritos por los medios de comunicación en el ejercicio de su libertad de expresión habían relatado la decisión de los tribunales nacionales de forma objetiva y la veracidad de dicha información no se había puesto en duda en ningún momento. Además, el grado de difusión por parte de los medios de comunicación de los archivos en línea que contenían los reportajes realizados en su momento sobre los demandantes era limitado y los demandantes no habían intentado dirigirse a los motores de búsqueda para reducir la posibilidad de acceso a sus informaciones personales.

Por todo ello, el TEDH desestimó las pretensiones de los demandantes y determinó que no se había producido una violación del art. 8 del Convenio.

\section{GARANTÍAS DE PROCEDIMIENTO EN CASO DE EXPULSIÓN DE EXTRANJEROS (ARTÍCULO 1 DEL PROTOCOLO N. ${ }^{\circ} 7$ )}

El último caso de esta sección es Ljatifi contra la Antigua República Yugoslava de Macedonia $(A R Y M)^{24}$. La demandante, nacional de Serbia, llegó con sus padres y hermanos a ARYM en 1999, cuando tenía 8 años de edad, huyendo de Kosovo. Ha residido allí desde entonces. En el año 2005 se le concedió asilo y un permiso de residencia. Mantenía una relación sentimental con un ciudadano macedonio con el que había tenido tres hijos (menores de edad y con nacionalidad macedonia). Su permiso de residencia fue extendido cada año hasta el 3 de febrero de 2014, cuando el ministro de Interior le retiró su condición de asilada por suponer un «riesgo para la seguridad nacional». La decisión de las autoridades fue precedida de una reunión con la demandante - que estuvo debidamente representada — donde confirmó su situación familiar y sus planes de contraer matrimonio con su pareja. La sospecha de que la demandante pudiera suponer un riesgo para la seguridad no se discutió en dicha entrevista. La decisión de las autoridades le daba un plazo de 20 días para abandonar el país.

La demandante presentó un primer recurso contra la decisión, desestimado por el Tribunal Contencioso-Administrativo sobre la base de que el

24 TEDH, Ljatifi v. the former Yugoslav Republic of Macedonia, no. 19017/16, $17 \mathrm{de}$ mayo de 2018. 
ministro había obtenido una nota clasificada por parte de la Agencia de Inteligencia que indicaba que la demandante representaba una amenaza para la seguridad nacional. El tribunal no proporcionó más detalles sobre dicho documento. La demandante volvió a recurrir, pero el Tribunal Superior Contencioso-Administrativo de nuevo desestimó la apelación con el argumento de que la decisión se había tomado sobre la base de información clasificada que probaba incuestionablemente que la presencia de la demandante en el país suponía una amenaza a su seguridad. Las razones por las que era considerada una amenaza nunca le fueron explicadas ni a nivel administrativo ni en los procedimientos judiciales posteriores. A pesar del carácter firme de la decisión dictada por el ministro de Interior, en el momento en el que el TEDH dictó sentencia la demandante todavía no había sido expulsada del país.

En el proceso ante el TEDH, la demandante alegó que el procedimiento en el que se le exigía abandonar el país no había contado con garantías mínimas. En particular, alegó que no existía prueba de que ella representara un riesgo para la seguridad nacional y que no se le había dado la oportunidad de ver o comentar los documentos en que se basaba la decisión de las autoridades. También que sus recursos judiciales no habían sido examinados de forma exhaustiva y rigurosa. El TEDH consideró que sus quejas se debían examinar desde el punto de vista del art. 1 del Protocolo n. ${ }^{\circ} 7$ del Convenio.

En primer lugar, el TEDH analizó la aplicabilidad del art. 1 del Protocolo n. ${ }^{\circ}$ 7. Tras destacar que las garantías específicas de dicha disposición eran aplicables a la expulsión de extranjeros que fueran residentes legales ${ }^{25}$, el TEDH subrayó que la demandante estaba en situación regular en el país y la decisión dictada por el ministro de Interior — que de forma expresa le ordenaba abandonar el país - se debía considerar como una medida de expulsión a todos los efectos prácticos (extremo que había sido negado por el Estado). El TEDH, por tanto, consideró que el art. 1 del Protocolo n. ${ }^{\circ} 7$ era aplicable a pesar de que, primero, la decisión que le ordenaba abandonar el país todavía no había sido ejecutada y, segundo, que el Estado aseguraba que no había riesgo de que fuera expulsada en el futuro. Fue decisivo para el TEDH el hecho de que la orden no se hubiera revocado o suspendido y que su ejecución no estuviera sujeta a ningún requisito formal, lo que significaba que la demandante estaba en riesgo de ser expulsada en cualquier momento.

En cuanto al fondo del asunto, el TEDH reiteró la importancia de cumplir con las garantías de procedimiento recogidas en los párrs. 1(a) y 1(b) del art. 1 del Protocolo n. ${ }^{0} 7$, es decir, el derecho del extranjero a exponer las razones que se opongan a su expulsión y a que su caso sea examinado. En este

25 TEDH, Ljatifi v the former Yugoslav Republic of Macedonia, cit., párr. 21. 
sentido hizo referencia a su jurisprudencia para destacar que en aquellos casos en los que la orden impugnada se basara en motivos de seguridad nacional, el requisito de previsibilidad no iba tan lejos como para obligar a los Estados a aprobar disposiciones legales que enumeren en detalle toda conducta que pueda dar lugar a una decisión de expulsar a una persona por motivos de seguridad nacional. No obstante, incluso en los casos donde la seguridad nacional está en juego, los conceptos de legalidad e imperio de la ley en una sociedad democrática exigen que las medidas de deportación que afecten a derechos fundamentales sean objeto de alguna forma de procedimiento contradictorio ante una autoridad independiente o un tribunal competente para examinar de forma efectiva las razones de aquella y revisar la prueba que resulte relevante, con las limitaciones procesales oportunas sobre el uso de información clasificada en caso de que fueran necesarias. La persona debe poder impugnar la afirmación de que la seguridad nacional está en juego. Mientras que la valoración por parte de las autoridades de lo que representa una amenaza a la seguridad nacional naturalmente tendrá un peso significativo, la autoridad independiente o tribunal debe poder reaccionar en casos donde la invocación de tales conceptos no tenga fundamento razonable en los hechos o revele una interpretación de «seguridad nacional» que sea ilegal o contraria al sentido común y arbitraria ${ }^{26}$.

El TEDH subrayó que la decisión del ministro que exigía a la demandante que abandonara el país había sido motivada únicamente por medio de la declaración general de que representaba un riesgo para la seguridad nacional, sin indicación alguna sobre los hechos que servían de base para tal valoración. Esto fue aceptado sin más en el procedimiento judicial posterior. Los tribunales solo añadieron que el ministro había llegado a tal conclusión sobre la base de un documento clasificado obtenido de la Agencia de Inteligencia. De esta forma, las autoridades no habían aportado la más ligera indicación sobre los motivos que justificaban su valoración y la mencionada nota de la Agencia de Inteligencia no se había puesto a disposición de la demandante (ni siquiera para su consulta bajo condiciones). A falta de una exposición mínima de los hechos que justificaban su valoración, la demandante no tuvo la posibilidad de presentar su caso de forma adecuada en el procedimiento judicial. A mayor abundamiento, de los documentos obrantes en el expediente nada hacía indicar que ni la nota de la Agencia de Inteligencia ni otros detalles de hecho hubieran sido facilitados a los tribunales nacionales de forma que hubieran podido verificar si la demandante realmente suponía un peligro para

26 TEDH, Ljatifi $v$. the former Yugoslav Republic of Macedonia, cit., párr. 35; véase también TEDH, C.G. and Others v. Bulgaria, no. 1365/07, 24 de abril de 2008. 
la seguridad nacional. Los tribunales nacionales se limitaron a llevar a cabo un examen puramente formal de la orden impugnada, sin llevar a cabo un escrutinio serio de la decisión.

Solo en el procedimiento llevado a cabo ante el TEDH, el Estado presentó una copia del citado documento clasificado. El TEDH pudo constatar que el único hecho que emergía de tal documento que pudiera sugerir que la demandante fuera un riesgo para la seguridad era su supuesto conocimiento de la implicación de otras personas en robos o encubrimiento. Ello vino a confirmar la conclusión anterior sobre la falta de justificación y la falta control de la decisión administrativa por parte de los tribunales.

Por todo lo anterior, el TEDH concluyó que ARYM había vulnerado los arts. 1(1)(a) y 1(1)(b) del Protocolo n. ${ }^{\circ}$ 7. Sobre ello es interesante destacar que el TEDH no condicionó la violación del Convenio a la posible expulsión de la demandante (en contraste con el enfoque del TEDH en casos de expulsión relativos a art. 3), lo que sin duda viene a resaltar la importancia de las garantías de procedimiento en caso de expulsión de extranjeros.

\section{REFERENCIAS AL DERECHO DE LA UE EN LA JURISPRUDENCIA DEL TEDH}

En esta sección se recogen algunas de las sentencias más relevantes donde la legislación de la UE y su aplicación han sido examinadas por el TEDH o han jugado un papel fundamental en la resolución de los casos. Esta sección muestra la importante relación entre el sistema europeo de protección de derechos humanos encarnado por el TEDH y la normativa y decisiones dictadas en el marco de la UE, con particular énfasis en la jurisprudencia del TJUE y de la interacción e influencia mutua entre ambos tribunales en materias relacionadas con los derechos fundamentales.

Un primer ejemplo es la sentencia recaída en el caso Vizgirda contra Esloveni $a^{27}$, en la que el TEDH analizó el deber de verificar las necesidades lingüísticas de demandados extranjeros de acuerdo con los arts. 6(1), 6(3)(a) y 6(3)(e) del Convenio. El demandante, de nacionalidad lituana, fue detenido en marzo de 2002 bajo sospecha de haber robado un banco en Eslovenia poco después de su llegada al país. Tras su detención fue informado de sus derechos y se le proporcionó servicio de interpretación al ruso, idioma que no era su

27 TEDH, Vizgirda v. Slovenia, no. 59868/08, 28 de agosto de 2018. Nótese que, a la fecha de redacción de la presente crónica, esta sentencia no ha alcanzado firmeza de conformidad con lo establecido en el art. 44(2) del Convenio. 
lengua materna. Los servicios de interpretación se extendieron desde la fase de investigación y el juicio hasta el procedimiento de apelación contra su condena. El demandante estuvo en todo momento asistido por abogado, con el que se comunicaba por medio de intérprete. Finalmente, el demandante fue condenado a más de ocho años de prisión.

En el procedimiento ante el TEDH el demandante se quejó de que no se pudo defender de forma efectiva en el proceso penal seguido contra él ya que el procedimiento y la traducción de los documentos no se hizo al lituano, su lengua materna, sino únicamente al ruso, un idioma que tenía dificultades considerables para comprender. El TEDH falló a favor del demandante y declaró que se había producido una violación de los arts. 6(1) y (3) del Convenio.

El TEDH aprovechó el presente caso para repasar y desarrollar su jurisprudencia relativa a los derechos de los acusados garantizados por los arts. 6(3) (a) y (e) del Convenio y las correspondientes obligaciones de las autoridades nacionales en procedimientos seguidos contra extranjeros. Para ello, el TEDH hizo especial referencia a instrumentos desarrollados en el marco de la UE, particularmente al preámbulo y los arts. 2 (derecho a interpretación), 3 (derecho a la traducción de documentos esenciales), 5 (calidad de la traducción y la interpretación) y 7 (llevanza de registros) de la Directiva 2010/64/UE relativa al derecho a interpretación y a traducción en los procesos penales ${ }^{28}$, y al preámbulo y los arts. 3 (derecho a la información sobre los derechos), 4 (declaración sobre los derechos en el momento de la detención) y 8 (verificación y recursos) de la Directiva 2012/13/UE relativa al derecho a la información en los procesos penales ${ }^{29}$. Ambos textos se habían incorporado al sistema jurídico esloveno mediante una modificación de la ley de procedimiento penal en vigor desde marzo de 2015.

En primer lugar, haciendo una revisión de su propia jurisprudencia, el TEDH destacó que todo acusado que no comprenda o no hable la lengua empleada en el proceso tiene derecho a los servicios gratuitos de un intérprete para que le sean traducidos o interpretados todos aquellos documentos o declaraciones dimanantes del procedimiento seguido contra él que sean necesarios para beneficiarse de un juicio justo ${ }^{30}$. Las obligaciones de los Estados no se limitarían a la mera designación de un intérprete, sino que implicarían un cierto grado de control posterior sobre la idoneidad de la interpretación ${ }^{31}$.

28 DO L 280, de 26 de octubre de 2010, p. 1.

29 DO L 141, de 1 de junio de 2012, p. 1.

30 TEDH, Vizgirda v. Slovenia, cit., párr. 77.

31 Ibid., párr. 79. 
En cuanto a la valoración de las necesidades de interpretación, el TEDH resaltó que corresponde a las autoridades implicadas en el procedimiento, particularmente los tribunales nacionales, determinar si se hace necesario designar un intérprete para asistir al acusado. Esta obligación no se limita a los casos donde el demandado extranjero solicita interpretación de forma expresa, sino que surge cuando haya razones para sospechar que el demandado no tiene un dominio suficiente del idioma del procedimiento, por ejemplo, cuando no sea nacional ni residente del país donde se lleva a cabo el procedimiento. Esta obligación también surge cuando se prevé el uso de un tercer idioma para la interpretación. En estos casos la competencia lingüística del demandado en dicho tercer idioma se debe comprobar antes de que se tome la decisión de utilizarlo ${ }^{32}$. El TEDH subrayó que la importancia de verificar las necesidades lingüísticas del demandado ha sido reconocida por la propia Directiva 2010/64/UE. El hecho de que el demandado tenga un dominio básico del idioma del procedimiento o del tercer idioma en el que se hace la interpretación no debería por sí mismo excluir que el acusado se beneficiara de la interpretación en un idioma que entendiera suficientemente bien para ejercer su derecho a la defensa de forma efectiva ${ }^{33}$. Eso sí, el Convenio deja amplia discreción a los Estados para desarrollar las medidas precisas que las autoridades nacionales deberán tomar para verificar el conocimiento lingüístico del demandado.

El TEDH hizo también hincapié en la necesidad de garantizar que cualquier sospechoso sea informado de su derecho a interpretación cuando se le acuse de un delito - en consonancia con el art. 3 de la Directiva 2012/13/ UE- y en la importancia de mantener un registro en el que quede constancia de cualquier procedimiento y decisión que se tome en relación con la verificación de las necesidades de interpretación, la notificación sobre el derecho a interpretación y la asistencia proporcionada por el propio intérprete ${ }^{34}$.

En lo que respecta a las circunstancias particulares del caso, el TEDH examinó primero si se había proporcionado un servicio de interpretación al demandante en un idioma sobre el que tuviera un dominio suficiente para su defensa - dado que el art. 6 del Convenio no requiere necesariamente que el demandado deba seguir el procedimiento en su lengua materna- y, en segundo lugar, si ello había menoscabado el carácter justo del proceso judicial en su conjunto. El TEDH concluyó que no se había probado que el demandante hubiera recibido una asistencia lingüística que le hubiera permitido participar activamente

32 Vizgirda v. Solvenia, cit., párr. 81.

33 Ibid., párr. 83.

34 Ibid., cit., párrs. 85-87. 
en el juicio, lo que consideró suficiente para determinar que el procedimiento en su conjunto había sido injusto y, por tanto, se había violado el Convenio. El fallo del TEDH se basó en lo siguiente: (i) las autoridades eslovenas habían dado por sentado que el demandante comprendía y podía seguir los procedimientos en ruso; (ii) las autoridades no habían verificado su competencia lingüística en dicho idioma y no constaba en los registros del procedimiento que el demandante hubiera sido consultado sobre si entendía suficientemente la interpretación y traducción al ruso; y (iii) aunque el demandante parecía poder hablar y comprender ruso, un hecho que no fue negado, el TEDH no encontró probado que su nivel en dicho idioma fuera suficiente para garantizar la justicia del procedimiento (haciendo referencia a, por ejemplo, las declaraciones del demandante en ruso).

Otro aspecto interesante del caso es que el demandante solo se quejó de que la interpretación y traducción del procedimiento se había producido al ruso (y no a su lengua materna) en su recurso ante el Tribunal Supremo y posteriormente ante el Tribunal Constitucional, razón por la que el Estado había alegado que el demandante no había agotado debidamente los recursos internos. El demandante no se había quejado de esto a lo largo de la investigación o el juicio ni en el procedimiento de apelación. Sobre ello el TEDH destacó que las autoridades no habían informado al demandante de su derecho a recibir interpretación en su lengua materna o en un idioma que comprendiera y enfatizó que las autoridades tenían la obligación de informar al demandante de tal derecho, obligación que también estaba recogida en derecho nacional. Esa falta de notificación junto con la vulnerabilidad del demandante - al ser un extranjero que había llegado a Eslovenia solo unos meses antes de su detención - y su limitado dominio del ruso fueron suficientes para justificar por qué el demandante no se había quejado o solicitado un intérprete diferente.

Por otro lado, en el caso O'Sullivan McCarthy Mussel Development Ltd contra Irlanda ${ }^{35}$, el TEDH examinó si las medidas adoptadas por el Estado demandado para cumplir con una sentencia del TJUE que declaraba que había infringido normativa de la UE sobre medio ambiente habían vulnerado el derecho de propiedad del demandante.

El demandante era una empresa que se dedicaba a la captura y el cultivo de mejillones en un puerto que había sido designado como zona especial de conservación de conformidad con la legislación nacional que daba cumplimiento a la normativa de la UE sobre protección del medio ambiente, particularmente la Directiva 79/409/CEE relativa a la conservación de las aves

35 TEDH, O'Sullivan McCarthy Mussel Development Ltd v. Ireland, no. 44460/16, 7 de junio de 2018. 
silvestres ${ }^{36}$ y la Directiva 92/43/CEE relativa a la conservación de los hábitats naturales y de la fauna y flora silvestres ${ }^{37}$. El demandante había obtenido todas las autorizaciones y permisos necesarios para llevar a cabo su actividad en el citado puerto.

El 13 de diciembre de 2007, como resultado de un procedimiento de infracción iniciado por la Comisión Europea en 2004 — de conformidad con el art. 226 del Tratado Constitutivo de la Comunidad Europea, actual art. 258 del Tratado de Funcionamiento de la Unión Europea (TFUE) - , el TJUE emitió un fallo mediante el que declaraba que Irlanda no había cumplido con sus obligaciones contraídas en virtud de las citadas directivas ${ }^{38}$. Las autoridades no habían realizado las requeridas evaluaciones de impacto ambiental de actividades acuícolas en lugares de especial protección, tales como las realizadas por la empresa demandante. En respuesta a la sentencia del TJUE y con el objeto de garantizar su cumplimiento, las autoridades, en consulta con la Comisión Europea, tomaron una serie de medidas que incluyeron la suspensión temporal de la autorización de la empresa demandante para la captura de mejillones en el citado muelle (no la relacionada con el cultivo). La empresa demandante entonces inició un procedimiento judicial contra el Estado con el objeto de reclamar compensación. En primera instancia el tribunal concluyó que había existido negligencia por parte de las autoridades e impuso una compensación a favor del demandante. En apelación, el Tribunal Supremo revocó la sentencia.

En el procedimiento ante el TEDH, el demandante alegó principalmente que su derecho de propiedad había sido vulnerado debido a la sustancial pérdida económica que había sufrido, atribuible directamente a la actuación de las autoridades nacionales, por la que no había recibido compensación alguna. El demandante también se quejó de la a su juicio excesiva duración de los procedimientos internos. El TEDH concluyó que no se había producido una violación del art. 1 del Protocolo n. ${ }^{\circ} 1$ ni del art. 6(1) del Convenio.

El TEDH en primer lugar examinó la aplicabilidad del art. 1 del Protocolo n. ${ }^{\circ} 1$, concluyendo que la prohibición temporal de capturar mejillones — actividad para la que previamente había recibido autorización- era una restricción impuesta sobre un permiso o licencia que afectaba al negocio acuícola y las actividades comerciales de la empresa demandante y, por tanto, suponía una injerencia en su derecho al respeto de sus «bienes» (possessions). Aunque la autorización realmente no se le había retirado o revocado, sino que

36 DO L 103, de 25 de abril de 1979, p. 1.

37 DO L 206, de 22 de julio de 1992, p. 7.

38 Sentencia de 13 de diciembre de 2007, Comisión/Irlanda, C-418/04, EU:C:2007:780. 
únicamente había sido objeto de una restricción temporal, en esencia ello supuso que la empresa demandante se viera privado de ella. Ahora bien, esta injerencia no se podía considerar una expropiación de facto - tal y como argumentaba el demandante- - sino como una medida «para la reglamentación del uso de los bienes» que se enmarca dentro del párrafo segundo del art. 1 del Protocolo n. ${ }^{\circ} 1$.

En cuanto al posible cumplimiento de las exigencias establecidas en el párrafo segundo del art. 1 del Protocolo n. ${ }^{\circ} 1$, el TEDH comenzó por analizar la legalidad y el objetivo de la injerencia. El TEDH dio por válido que la suspensión temporal de la captura de mejillones se había llevado a cabo de conformidad con normativa que resultó suficientemente accesible, precisa y previsible. La injerencia, además, tenía un objetivo legítimo al estar destinada a proteger el medio ambiente - objetivo que el TEDH destacó por su importancia- y cumplir con las obligaciones del Estado de acuerdo al derecho de la UE.

El análisis del TEDH se centró entonces en el examen de la proporcionalidad de la medida. En primer lugar, el TEDH tuvo que responder al argumento presentado por el Estado de que la injerencia derivaba directamente de la sentencia del TJUE tras el procedimiento de infracción, por lo que las autoridades nacionales no tuvieron margen de maniobra en su actuación. Ello conllevaba que fuera aplicable el principio de "presunción de protección equivalente» del ordenamiento jurídico de la UE de conformidad con la jurisprudencia del $\mathrm{TEDH}^{39}$. El TEDH desestimó tal argumento al considerar que aunque la sentencia era obligatoria para el Estado demandado, este tenía cierto margen de maniobra a la hora de determinar cómo garantizar su cumplimiento. La obligación del Estado derivaba principalmente del art. 6(3) de la Directiva 92/43/CEE y, más directamente, de la sentencia del TJUE, pero en ambos casos únicamente se imponían obligaciones de resultado y no se exigía llevar a cabo su cumplimiento de una determinada manera. Por consiguiente, el Estado retuvo cierto margen de maniobra, como demuestra el hecho de que entablara negociaciones con la Comisión Europea.

A juicio del TEDH, la injerencia en el derecho de propiedad de la empresa demandante había sido proporcionada. Para ello tuvo en cuenta que, al menos desde que se dictara la sentencia del TJUE (si no antes, cuando la Comisión Europea inició el procedimiento de infracción), la empresa — como operador comercial— debería haber sido consciente del posible riesgo de que

39 Sobre este principio véase TEDH, Bosphorus Hava Yollar Turizm ve Ticaret Anonim Şirketi v. Ireland [GC], no. 45036/98, 30 de junio de 2005; y Avotiňš v. Latvia [GC], no. 17502/07, 23 de mayo de 2016. 
sus actividades se vieran interrumpidas o sufrieran consecuencias. Aunque la injerencia impugnada incidió negativamente en el negocio del demandante, el TEDH no consideró probado que la pérdida de beneficios fuera el resultado inevitable del cierre temporal del muelle. Las actividades de la compañía no fueron completamente interrumpidas en 2008 ya que la empresa pudo continuar con el cultivo de mejillones (los beneficios de ese año no se vieron afectados) y al año siguiente pudo reanudar su actividad comercial habitual gracias a las negociaciones del Estado con la Comisión Europea, en las que además las autoridades dieron prioridad al muelle donde el demandante ejercía su actividad. Las repercusiones de la sentencia del TJUE no se limitaron a la compañía demandante, sino que tuvieron una dimensión nacional, afectando también a otros muchos lugares de especial protección en todo el país. En opinión del $\mathrm{TEDH}$, el cumplimiento de la sentencia requirió medidas a gran escala que debían ser tomadas en un plazo aceptable, por lo que era un asunto de interés general para la comunidad que otorgaba un amplio margen de apreciación a las autoridades nacionales. Este amplio margen a favor de los Estados venía reforzado en casos como el presente relativos a la implementación de políticas de protección medioambiental, objetivo con una posición preeminente para el interés general.

En conclusión, en lo que concierne a la queja relativa al art. 1 del Protocolo n. ${ }^{\circ}$, el TEDH no consideró que la injerencia hubiera constituido una carga individual y excesiva para la compañía demandante. Las medidas implementadas por el Estado demandado habían logrado alcanzar un justo equilibrio entre el interés general y la protección de los derechos del propio demandante, desestimándose las pretensiones de este último.

En relación con la alegada duración excesiva del procedimiento en vulneración del art. 6(1) del Convenio, el TEDH tomó en consideración que el procedimiento había durado siete años, periodo comprendido entre la demanda del demandante (12 de febrero de 2009) y la decisión del Tribunal Supremo (26 de febrero de 2016). El TEDH reconoció que la duración del caso había sido prolongada, pero concluyó que no fue excesiva a la luz de las circunstancias concretas del caso. El TEDH destacó la complejidad del caso, tanto en aspectos de hecho - que exigieron pruebas científicas- como de derecho - planteando interrogantes significativos sobre derecho nacional y de la UE-. En lo concerniente a la actuación de las partes en el procedimiento, aunque por lo general el demandante había actuado con la debida diligencia, ligeros retrasos en varias actuaciones procesales fueron imputables a él. Por otro lado, el procedimiento no sufrió retrasos significativos atribuibles a las autoridades y tribunales nacionales, habiéndose incluso dado prioridad al caso ante el Tribunal Supremo. Por último, en lo que concierne a lo que estaba en juego para la compañía demandante, el TEDH concluyó que no se podía con- 
siderar que el procedimiento hubiera tenido tal nivel de urgencia que hubiera hecho necesaria una especial diligencia por parte de las autoridades.

\section{ESPAÑA Y EL TEDH}

Durante el segundo cuatrimestre de 2018 el TEDH no ha dictado ninguna sentencia relativa a demandas presentadas contra España. Únicamente se han pronunciado dos decisiones de inadmisibilidad.

El caso Lázaro Laporta ${ }^{40}$ fue declarado inadmisible por ser incompatible ratione materiae con las disposiciones del Convenio. El recurso fue presentado por un profesor de la Universidad Politécnica de Valencia contra el que se abrió un expediente disciplinario por haber accedido sin autorización a las cuentas de correo de algunos de sus compañeros. Dicho procedimiento se suspendió posteriormente a la vista de que se habían abierto diligencias penales contra el demandante por los mismos hechos. El procedimiento judicial finalizó con la absolución del demandante —al que se le habían imputado delitos de descubrimiento y revelación de secretos y un delito contra la propiedad intelectual - al entender los tribunales nacionales (la Audiencia Provincial de Alicante y el Tribunal Supremo) que los hechos no eran constitutivos de delito alguno ya que el acceso a las cuentas de correo electrónico, sin consentimiento, se había producido sobre correos institucionales que no se utilizaban de forma personal o recogiendo datos que afectaran a la intimidad o privacidad de sus titulares. Así, aunque los tribunales reconocieron que pudo existir una afectación de datos sometidos a confidencialidad, consideraron que no se había producido una vulneración de la intimidad, de ahí que la conducta del acusado hubiera podido dar lugar a acciones civiles y disciplinarias, pero no al más restrictivo reproche penal. No obstante, los tribunales consideraron probado que entre el año 2013 y junio de 2015 el demandante (funcionario público), utilizando las instalaciones y equipamiento de la universidad, había accedido a los correos electrónicos de varios profesores universitarios indebidamente, de forma sistemática y sin el consentimiento de sus titulares.

Las sentencias fueron incorporadas al expediente y las autoridades universitarias reanudaron el procedimiento administrativo que había sido previamente suspendido. Mediante una resolución de fecha 1 de diciembre de 2011, el rector de la universidad resolvió, sobre la base de los hechos declarados probados en el procedimiento penal, sancionar al demandante con la suspensión de funciones durante un periodo de cuatro años por la comisión de una

40 TEDH, Lázaro Laporta v. Spain (dec.), no. 32754/16, 3 de julio de 2018. 
falta muy grave de obstaculización del ejercicio de las libertades públicas al suponer su conducta una intromisión en el secreto de las comunicaciones. El demandante presentó una demanda contra la resolución que resultó estimada por el Juzgado de lo Contencioso-Administrativo al considerar este que el procedimiento disciplinario había caducado por no haber resultado procedente la suspensión del expediente sancionador una vez incoado el procedimiento penal. El Tribunal Superior de Justicia de Valencia posteriormente estimó el recurso de apelación interpuesto por la universidad y revocó la sentencia, confirmando la sanción disciplinaria impuesta al demandante.

Ante el TEDH el demandante adujo que se le había impuesto una sanción administrativa tras haber sido absuelto por los mismo hechos en el procedimiento penal anterior, en violación del principio non bis in idem $\mathrm{y}$, por tanto, vulnerando los arts. 7 del Convenio y 4 del Protocolo n. 7.

El TEDH analizó si la sanción impuesta al demandante se podía considerar «penal» en el sentido dado por el Convenio de tal forma que las disposiciones que fundamentaban la demanda fueran aplicables al caso concreto. Para ello se valió de los criterios ya consolidados en su jurisprudencia, los denominados "criterios Engel», esto es, la clasificación jurídica de la infracción en el derecho nacional, la naturaleza misma de la infracción y el nivel de gravedad de la sanción. El TEDH destacó que los procedimientos disciplinarios, en principio, no decidían sobre el fundamento de una acusación en materia penal. Consideró en primer lugar que la sanción estaba contemplada como parte del régimen disciplinario de los funcionarios de la Administración del Estado. Era únicamente aplicable a infracciones cometidas por funcionarios públicos en el ejercicio de sus funciones, destacando que los tribunales nacionales habían establecido una distinción entre los intereses jurídicos protegidos en el procedimiento penal y el disciplinario. El TEDH razonó que la sanción impuesta al demandante era característica de una falta disciplinaria y no podía ser considerada equivalente a una sanción penal. Además, había sido impuesta por una infracción muy grave, sobre la base de hechos que se habían declarado probados en el procedimiento penal seguido contra el propio demandante. Sobre el nivel de gravedad de la sanción, el TEDH también destacó que no había supuesto la medida más dura en la escala de sanciones disciplinarias susceptible de aplicarse. Por todo ello, el TEDH concluyó que la sanción impuesta al demandante no tenía naturaleza penal y por tanto los arts. 7 del Convenio y 4 del Protocolo n. ${ }^{\circ} 7$ no eran aplicables.

Por otro lado, el TEDH (en formación de comité) decidió archivar el caso Omorefe contra España ${ }^{41}$ de conformidad con el art. 37(1)(a) del Conve-

41 TEDH, Omorefe v. Spain (dec.), no. 69339/16, 12 de junio de 2018. 
nio al considerar que la demandante, de nacionalidad nigeriana, ya no estaba dispuesta a mantener la demanda. La demandante se había quejado de que el Estado había vulnerado el art. 8 del Convenio al no haber cumplido sus obligaciones positivas por no tomar ninguna medida para favorecer la relación entre ella y sus hijos. Sin embargo, al no haber enviado sus observaciones en respuesta a las presentadas previamente por los representantes del Estado, el TEDH consideró que no estaba justificado continuar con el examen de la demanda. 